\title{
A profile of The Clinical Course of Cognition and Comorbidity in Mild Cognitive Impairment and Dementia Study (The 4C study): two complementary longitudinal, clinical cohorts in the Netherlands
}

Weiqi Liao ${ }^{1 \dagger}$, Renske E. G. Hamel ${ }^{2 \dagger}$, Marcel G. M. Olde Rikkert ${ }^{3}$, Saskia M. Oosterveld ${ }^{1}$, Pauline Aalten ${ }^{2}$, Frans R. J. Verhey ${ }^{2}$, Philip Scheltens ${ }^{4}$, Nicole Sistermans ${ }^{4}$, Yolande A. L. Pijnenburg ${ }^{4}$, Wiesje M. van der Flier ${ }^{5}$, Inez H. G. B. Ramakers ${ }^{2}$ and René J. F. Melis ${ }^{1 *}$

\begin{abstract}
Background: Heterogeneous disease trajectories of mild cognitive impairment (MCl) and dementia are frequently encountered in clinical practice, but there is still insufficient knowledge to understand the reasons and mechanisms causing this heterogeneity. In addition to correlates of the disorder, patient characteristics such as their health status, social environment, comorbidities and frailty may contribute to variability in trajectories over time. The current paper outlines the study design and the study population of and provides an overview of the data collected in the Clinical Course of Cognition and Comorbidity in Mild Cognitive Impairment (4C-MCl cohort, $n=315$ ) and Dementia (4C-Dementia cohort, $n=331$ ) Study.

Methods: The two complementary longitudinal cohorts part of the 4C study began enrolment in March 2010. Participants were prospectively recruited from three collaborating Dutch Alzheimer Centers, with three annual follow-up assessments after baseline. Extensive neuropsychological assessments, and detailed profiling of comorbidities, health and frailty at each follow up were the key features of the $4 \mathrm{C}$ study. As such, the $4 \mathrm{C}$ study was designed to study if and how patients' comorbidities and frailty are associated with the course of $\mathrm{MCl}$ and dementia measured with a comprehensive and multidimensional set of outcomes including cognition, daily functioning, quality of life, behavioral disturbances, caregiver burden, institutionalization and death and whether the effects of medical health and frailty differ between $\mathrm{MCl}$ and dementia stages of cognitive disorders.

(Continued on next page)
\end{abstract}

\footnotetext{
* Correspondence: rene.melis@radboudumc.nl

${ }^{\dagger}$ Equal contributors

${ }^{1}$ Radboud Institute of Health Sciences, Department of Geriatric Medicine \& Radboudumc Alzheimer Centre, Radboud University Medical Center, PO Box 9109(House post 925), 6500 HB Nijmegen, The Netherlands

Full list of author information is available at the end of the article
} 
(Continued from previous page)

Conclusion: Sampled in a clinical setting, the $4 \mathrm{C}$ study complements population-based studies on neurodegenerative disorders in terms of the type of assessment (e.g. comorbidity, frailty, and functional status were repeatedly assessed). The $4 \mathrm{C}$ study complements available clinical cohorts of $\mathrm{MCl}$ and dementia patients, because the exclusion criteria were kept to a minimum, to obtain a sample that is representative for the average patient visiting a memory clinic.

Keywords: Mild Cognitive Impairment (MCI), Dementia, Disease progression, Cognition, Comorbidity, Frailty

\section{Background}

Dementia is a syndrome of impaired cognitive functioning that interferes with living independently. It is a global public health issue with numbers of people suffering from dementia estimated to increase from 46.8 million in 2015 to 74.7 million in 2030, and to 131.5 million in 2050 worldwide [1]. Mild cognitive impairment $(\mathrm{MCI})$ is a state of impaired cognitive performance that does not significantly interfere with independent living and is a risk factor for developing dementia. Both in $\mathrm{MCI}$ and dementia, progression over time varies tremendously among patients. Some patients with MCI progress precipitately after the diagnosis, whereas a substantial proportion of patients does not develop dementia even after a prolonged period of up to 10 years [2]. In the stage of a clinically manifest dementia syndrome, studies have shown huge differences in rate of decline over time, even within a well-characterized cohort of persons with dementia of the Alzheimer type [3]. Understanding the causes leading to heterogeneous trajectories is essential for healthcare professionals to deliver personalized care and to maximally delay the progression of the condition. However, current knowledge cannot explain the phenotypical heterogeneity present in patients. Part of the heterogeneity in dementia presentation might be attributed to different etiologies, such as (the combination of) Alzheimer's or vascular pathology. To further increase our understanding of the observed heterogeneity, a theoretical framework has been developed that posits dementia as a multi-causal, complex and dynamic disorder with involvement of many body systems/organs at different levels, rather than a disease with a single pathology [4]. The majority of patients with MCI and dementia are aged and may experience different levels of frailty and suffer from a considerable number of comorbidities that may affect clinical phenotype [5-9], How these patient characteristics influence the development and prognosis of the disorder is largely unknown. With the aim to evaluate the impact of comorbidity and frailty on the course of MCI and dementia, the Clinical Course of Cognition and Comorbidity in Mild Cognitive Impairment and Dementia Study (4C study) was conducted. The current paper outlines the study design, the study population and an overview of the data collected.

\section{$4 C$ study research objectives}

As part of the $4 \mathrm{C}$ study two complementary multicenter longitudinal cohorts were sampled in the Netherlands, with the following research objectives:

1. Explore heterogeneity in trajectories of progression in multiple outcomes, survival and institutionalization, as well as conversion rates (MCI to dementia and back and between different nosological subtypes) in persons with newly diagnosed $\mathrm{MCI}$ and dementia;

2. Investigate whether comorbidity (number and severity of chronic comorbidities and presence of certain comorbidities) and frailty influenced the course and outcome of MCI and dementia;

3. Investigate predictors of transitions (conversions, institutionalization, death) as well as compare outcome trajectories right before and after transitions.

4. Investigate predictors and outcome trajectories of persons who did not convert from MCI to dementia and who were not institutionalized

5. Develop prognostic rules for conversion and individual decline in cognition, behavior, and daily functioning, institutionalization and death.

These research objectives are studied both in the separate samples of MCI and dementia as well as in the combined sample to evaluate differences between these stages of increasingly severe cognitive decline.

\section{Construction and content}

\section{Study design and participants}

The MCI and Dementia cohort of the $4 \mathrm{C}$ study were similar in study design and implementation, but were conducted in different disease stages. Both cohorts aimed to enroll 300 participants at baseline, equally from the three participating centres Alzheimer Center of the VU University Medical Center Amsterdam, Alzheimer Centre Limburg of the Maastricht University Medical Center and Radboudumc Alzheimer Center, Radboud university medical center. The departments hosting the three memory clinics have a background in neurology (Amsterdam), old age psychiatry (Maastricht) and geriatric medicine (Nijmegen). 
The study base of this cohort study were all persons referred to one of the three memory clinics by their primary care physician or referring medical specialist. The inclusion period ran from the March 2010 until May 2011. All consecutive referrals were prospectively evaluated for study eligibility during that period.

People with a new diagnosis of dementia made during this memory clinic visit were eligible for the Dementia cohort. Patients who had subjective cognitive decline or objective cognitive impairments based on neuropsychological test results, but did not fulfill the diagnostic criteria for dementia were eligible for the MCI cohort. The exact eligibility criteria for the $4 \mathrm{C}-\mathrm{MCI}$ and the 4C-Dementia cohorts are shown in Table 1. As such the inclusion was broader than in most studies on $\mathrm{MCI}$ and dementia since comorbidities were allowed, thus resulting in a patient sample that was more representative for regular patient groups.

The clinician responsible for the care during the memory clinic visit asked whether patients would be willing to consider participation in the $4 \mathrm{C}$ study. If so, they were provided with written study information and a visit was scheduled with a research assistant to obtain written informed consent from the participant and an informant and to complete the baseline assessments. In order to be eligible, an informant had to be available and have contact with the participant for at least once a week. Almost all informants (about 90\%) were either the participant's partner or offspring, often also serving in a caregiving role. Not all participants had an informant who provided care that qualified as informal caregiving. However, if such a person could be identified, this person was asked as the informant. As a rule the same informant participated across the follow ups. In a small number of cases exceptions were allowed to minimize missings.

\section{Data collection}

The participants were scheduled to have three annual follow-ups after the baseline measurement during visits at the memory clinic. Annual follow-ups had to be conducted within a 3 months' time frame around the dates of an annual schedule. The last assessment in the participants who last entered the study was conducted in August 2014. The flowcharts for both cohorts are shown in Figs. 1 and 2.

A multidisciplinary team consisting of physicians, neuropsychologists and research assistants collaborated in the standardized collection of the baseline and follow up data with the patient and the informant. As such, the multidisciplinary team (led by a consultant neurologist, psychiatrist or geriatrician respectively) responsible for the clinical care of the participant at the memory was also responsible for the research data collection. Data were collected on demographics, syndrome diagnosis, cognitive functioning, health conditions, functional abilities, neuropsychiatric symptoms, quality of life, and care resource use. An overview of the collected data per measurement, who was the source of the information and who collected the information is presented in Table 2. The assessor scored the reliability of the participant's answers.

In order to minimize the dropout rate, home visits by a researcher trained as a psychologist were implemented for those participants who were willing to continue participation in the study but unable to visit the memory clinics. In case participants needed an institutionalization, they continued with the study. The possibility to do the follow up assessment during a home visit also facilitated this.

\section{Syndrome diagnosis of $\mathrm{MCl}$ and dementia}

Syndrome diagnoses were made at baseline and reviewed at every follow-up visit based on clinical

Table 1 Eligibility criteria for the 4C Study

\begin{tabular}{|c|c|c|}
\hline Inclusion criteria & The $4 \mathrm{C}-\mathrm{MCl}$ cohort & The 4C-Dementia cohort \\
\hline - Cognitive performance & $\begin{array}{l}\text { subjective cognitive complaints and/or objective } \\
\text { cognitive impairments }\end{array}$ & objective cognitive impairments \\
\hline • Fulfil the DSM-IV diagnostic criteria for dementia [12] & No & Yes \\
\hline - Clinical Dementia Rating (CDR) Scale [34] & $0-0.5$ & $0.5-2$ \\
\hline • Mini Metal State Examination (MMSE) score [35] & Not specified & $\geq 10$ \\
\hline - Age & $\geq 55$ years & Not specified \\
\hline \multicolumn{3}{|l|}{ Exclusion criteria (similar for both cohorts) } \\
\hline \multicolumn{3}{|c|}{ - The absence of a reliable informant (who has contact with the participant for at least once a week); } \\
\hline \multicolumn{3}{|c|}{$\begin{array}{l}\text { - If the participant was expected unable to have at least one follow-up based on clinical judgment of the physician responsible for the care of } \\
\text { the patient at the memory clinic; }\end{array}$} \\
\hline \multicolumn{3}{|c|}{$\begin{array}{l}\text { - The presence of other neurological disorders that could cause cognitive impairment or affect cognitive performance, such as Parkinson's } \\
\text { Disease, Huntington's Disease, Normal Pressure Hydrocephalus (NPH), Korsakov's syndrome, and a medical history of brain tumour, encephalitis } \\
\text { or epilepsy. However, participants suffering from other cerebrovascular or psychiatric disorders were included in the studies. }\end{array}$} \\
\hline
\end{tabular}




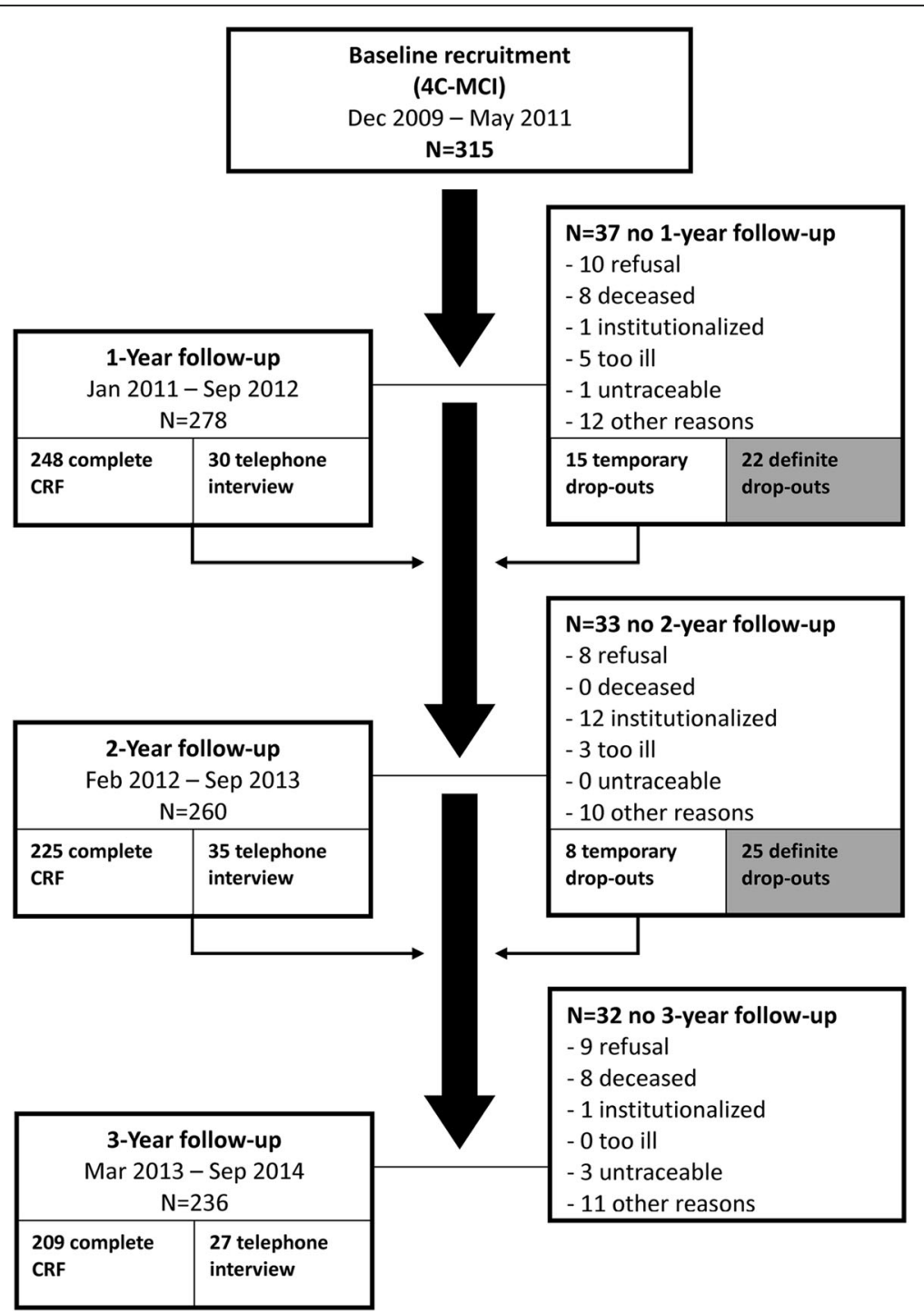

Fig. 1 Flowchart of the $4 \mathrm{C}-\mathrm{MCl}$ cohort

assessment by the physician and the multidisciplinary team. For the minority of cases in whom the follow up assessments were operationalized as a home visit, the diagnosis review was determined by a physician from the research data. The diagnosis of MCI was based on Petersen criteria [10] and was operationalized as a zscore lower than -1.5 SD (Dutch norm) on any of the cognitive tests (see below). Subjects with cognitive complaints without such a verified impairment on cognitive tests were categorized as subjective cognitive decline (SCD) [11]. The diagnosis of dementia was based on DSM-IV criteria [12]. Nosological dementia diagnoses were made according to standardized clinical criteria for AD (NINCDS-ADRDA criteria [13]), vascular dementia (NINDS-AIREN criteria [14]), frontotemporal dementia [15], and dementia with Lewy bodies [16].

\section{Cognitive assessment}

Data about the self-reported onset (gradual or sudden), course (stable, fluctuating or progressively deteriorated) and duration of the cognitive complaints were collected. In addition, patients were asked whether they had noticed a change in four cognitive functions (memory, concentration, mental capacity, and vitality) during the last year [17]. Change in each function was scored on a 7-point Likert scale ranging from -3 (very strong decline) to +3 (very strong improvement). If the participant was unable to answer by himself, the informant reported it based on daily contact and observation.

The neuropsychological assessment consisted of the same standardized battery of cognitive tests as used in the Dutch Parelsnoer Instituut (www.parelsnoer.org), covering the following domains: global cognition, episodic memory, implicit visual learning, working memory, word fluency, 


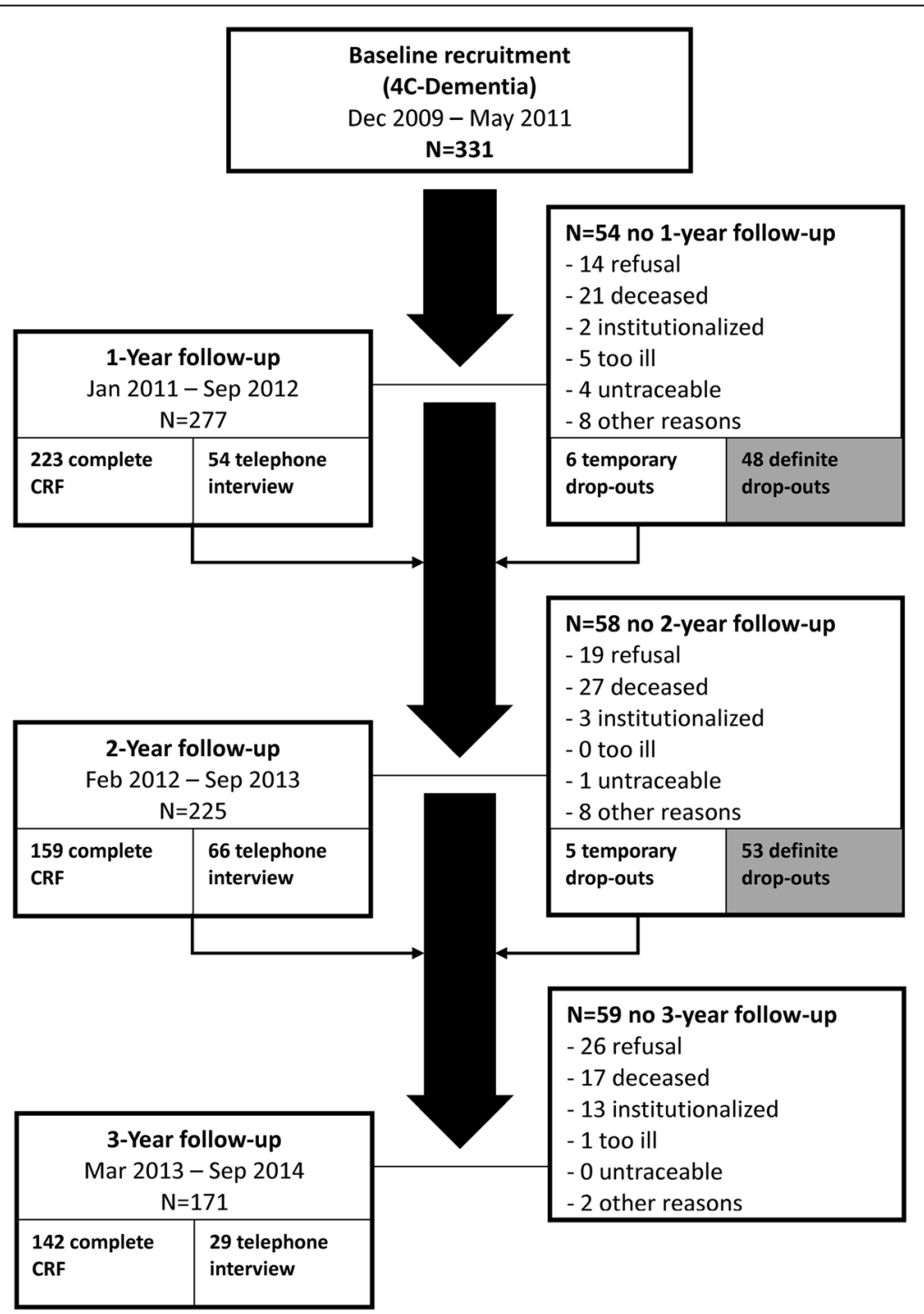

Fig. 2 Flowchart of the 4C-Dementia cohort

information processing speed, attention, executive functioning and visual perception (Table 3) [17].

\section{Further assessments and questionnaires}

Height, weight, and, waist circumference, systolic and diastolic blood pressure of the participants were recorded. Smoking and drinking status, the type, quantity and frequency of tobacco and alcohol consumption were asked. The physician structurally reviewed the patient's personal medical history at baseline, and particularly queried extrapyramidal symptoms, gait disturbances, and family history. Newly diagnosed diseases were updated at every follow-up visit, also recording any taken medication and each hospitalization (Table 4).

The Cumulative Illness Rating Scale for Geriatrics (CIRS-G) was used to further quantitatively measure disease burden and reflects the number and severity of the diseases [18]. Using CIRS-G, all diseases were classified into 14 organ systems: cardiac (heart only), vascular, hematologic, respiratory, ophthalmologic and otorhinolaryngologic, upper gastrointestinal, lower gastrointestinal, hepatic and pancreatic, renal, genitourinary, musculoskeletal and tegumental, neurologic, endocrine/metabolic and breast, and psychiatric. If a patient had multiple diseases in a single category, the most severe one was appraised. The severity of impairment was rated with a $0-4$ grading scale from no problem to extremely severe problem (e.g. organ failure) resulting in a total score ranging from 0 to 56. The CIRS-G can be adapted as a measure of pure physical functioning in the $4 \mathrm{C}$ studies by excluding the psychiatric category, since this category includes cognition related comorbidities. The total score runs from 0 to 52 . 
Table 2 Contents of data collection in the 4C studies

\begin{tabular}{|c|c|c|c|c|c|c|}
\hline & Baseline & 12 months & 24 months & 36 months & Assessed by & Source \\
\hline Informed consent & $\sqrt{ }$ & & & & Research assistant & Participant and informant \\
\hline Demographics & $\sqrt{ }$ & $\sqrt{ }$ & $\sqrt{ }$ & $\sqrt{ }$ & Research assistant & Participant and informant \\
\hline MMSE [35] & $\sqrt{ }$ & $\sqrt{ }$ & $\sqrt{ }$ & $\sqrt{ }$ & Physician & Participant \\
\hline CDR [34] & $\sqrt{ }$ & $\sqrt{ }$ & $\sqrt{ }$ & $\sqrt{ }$ & Physician & Participant and informant \\
\hline Subjective cognitive functioning [17] & $\sqrt{ }$ & $\sqrt{ }$ & $\sqrt{ }$ & $\sqrt{ }$ & Physician & Informant \\
\hline Neuropsychological assessment & $\sqrt{ }$ & $\sqrt{ }$ & $\sqrt{ }$ & $\sqrt{ }$ & Psychologist & Participant \\
\hline Physical examination \& structural medical review & $\sqrt{ }$ & $\sqrt{ }$ & $\sqrt{ }$ & $\sqrt{ }$ & Physician & Participant and informant \\
\hline Medications (prescribed \& taken) & $\sqrt{ }$ & $\sqrt{ }$ & $\sqrt{ }$ & $\sqrt{ }$ & Physician & Participant and informant \\
\hline Hospitalization (if any) & & $\sqrt{ }$ & $\sqrt{ }$ & $\sqrt{ }$ & Research assistant & Participant and informant \\
\hline Syndromal diagnoses & $\sqrt{ }$ & $\sqrt{ }$ & $\sqrt{ }$ & $\sqrt{ }$ & Physician & Participant and informant \\
\hline Comorbidities (CIRS-G) [18] & $\sqrt{ }$ & $\sqrt{ }$ & $\sqrt{ }$ & $\sqrt{ }$ & Physician & Participant and informant \\
\hline Frailty (Fried criteria + Frailty Index) $[19,20]$ & $\sqrt{ }$ & $\sqrt{ }$ & $\sqrt{ }$ & $\sqrt{ }$ & Research assistant & Participant and informant \\
\hline DAD (disability assessment) [21] & $\sqrt{ }$ & $\sqrt{ }$ & $\sqrt{ }$ & $\sqrt{ }$ & Research assistant & Informant \\
\hline GDS-15 (depression, self-reported) [22] & $\sqrt{ }$ & $\sqrt{ }$ & $\sqrt{ }$ & $\sqrt{ }$ & Research assistant & Participant \\
\hline NPI (neuropsychiatric symptoms) [23] & $\sqrt{ }$ & $\sqrt{ }$ & $\sqrt{ }$ & $\sqrt{ }$ & Research assistant & Informant \\
\hline Euroqol 5D [24] & $\sqrt{ }$ & $\sqrt{ }$ & $\sqrt{ }$ & $\sqrt{ }$ & Research assistant & Informant \\
\hline Care resource use & $\sqrt{ }$ & $\sqrt{ }$ & $\sqrt{ }$ & $\sqrt{ }$ & Research assistant & Informant \\
\hline Refusal or withdrawal data & $\sqrt{ }$ & $\sqrt{ }$ & $\sqrt{ }$ & $\sqrt{ }$ & Research assistant & Participant and informant \\
\hline Institutionalization (outcome \& date) & & $\sqrt{ }$ & $\sqrt{ }$ & $\sqrt{ }$ & Research assistant & Participant and informant \\
\hline Death (outcome \& date) & & $\sqrt{ }$ & $\sqrt{ }$ & $\sqrt{ }$ & Research assistant & Informant \\
\hline
\end{tabular}

Table 3 Standardized cognitive tests and the corresponding domains

\begin{tabular}{ll}
\hline Cognitive domain(s) & Neuropsychological tests \\
\hline Global cognition & Mini Mental State Examination \\
(MMSE) [35] & 15-Word Verbal Learning Test (VLT) \\
Episodic memory & recall and delayed recognition [36]
\end{tabular}

Implicit associative visual learning Visual Association Test (VAT), short version [37]

Working memory

Verbal word fluency/semantic memory

Digit Span subtest (forwards and backwards) of the Wechsler Adult Intelligence Test (3rd Edition) [38]

Information processing speed

$60 \mathrm{~s}$ animal fluency [39]

Letter Digit Substitution Test (LDST) [40]

Information processing speed attention and executive functioning/response inhibition

Information processing speed attention and executive functioning/concept shifting

Visual perception

Trail Making Test (TMT) parts $A \& B$ [42]

Visual Object and Space Perception
Frailty was operationalized using the five physical criteria developed by Fried (2001) [19]. To that aim, grip strength (dominant hand, average of two measures) was measured using a Jamar ${ }^{\circ}$ hand dynamometer and gait speed while walking at usual speed across $4.5 \mathrm{~m}$ (average of two measures). Unintentional weight loss and fatigue (two questions of Center for Epidemiologic Studies Depression Scale (CES-D)) were evaluated using questionnaires. Impaired physical activity was evaluated by

Table 4 Structural medical review of participant's health conditions

\begin{tabular}{ll}
\hline Body systems & Concerned diseases \\
\hline Cardiovascular & $\begin{array}{l}\text { angina, myocardial infarction, angioplasty/stent, } \\
\text { coronary bypass surgery, carotid stenosis, } \\
\text { hypertension, heart failure, others }\end{array}$
\end{tabular}

Cerebrovascular transient ischemic attack (TIA), cerebrovascular accidents (infarction, bleeding), reversible ischemic neurologic deficit (RIND), others

Endocrinal diabetes mellitus, hypothyroidism, hyperthyroidism, obesity, others

Psychiatric depression, psychosis, delirium, others

Somatic chronic obstructive pulmonary disease (COPD), kidney problems, liver problems, others

Medications

the names, doses, frequencies and the indications of the medications battery (VOSP, Optional) Subtests of dot counting and incomplete letters [43]
Hospitalization the primary diagnosis, acute or routine medical care, the treating department, the total number of nights spent in the hospital 
asking whether the participant yes or no exercised, performed household chores, did odd jobs around the house or gardened. If they did any of these, this item was scored as not impaired. If participants did not engage in any of these activities they were asked to rate the time per week engaged in biking or walking. Multiplying these estimates by 4 and $3.5 \mathrm{kcal} / \mathrm{min}$ respectively and summing them resulted in the estimated weekly energy expenditure related to biking and walking. If this estimate was below 393 or $280 \mathrm{kcal} /$ week for men and women respectively, physical activity was scored as impaired. A frailty index based on accumulated deficits also was operationalized from the $4 \mathrm{C}$ data [20].

The Disability Assessment for Dementia (DAD) scale, measuring both basic and instrumental activities of daily living (ADL, IADL), was used to evaluate the severity of impairment in everyday functioning through a structured interview with the informant [21]. The participants' abilities to perform ten different (I)ADL activities in the 2 weeks prior to the assessment were rated. The final DAD score was converted to a percentage from 0 to 100, in which a higher percentage indicates a higher level of daily functioning.

The 4C study used the Geriatric Depression Scale (GDS-15) to assess the presence and severity of depressive symptoms in older persons [22]. The Neuropsychiatric Inventory (NPI) was used to characterize the psychopathology of the patient through a structured interview with the informant, assessing 12 common neuropsychiatric symptoms [23]. A screening question for each neuropsychiatric symptom was asked to confirm the presence of the symptom before rating the frequency (1-4, rarely-very often), severity (1-3, mildsevere), and burden ( $0-5$, not at all-extremely) for the informant. The total NPI score ranged from 1 to 144 .

The EQ-5D was used to measure health-related quality of life and results in a score of $0-100$, where higher scores indicate better functioning [24]. The EQ-5D was rated by the patient and by the informant: for the situation of the patient and for the informant him-/herself.

Besides patient and disease related data, also data about the patient's care resource use was investigated by assessing the number of visits to the general practitioner, home care, day care, institutionalized care, hospital in- and outpatient, emergency care, other professionals, informal care, medical goods, and out-of-pocket expenditures using an informant questionnaire.

\section{Refusal or withdrawal, minimum but essential data collected for research}

The reasons for dropout were collected and categorized. The attrition is shown in the flowchart of Figs. 1 and 2. With their consent, the study investigators made efforts to collect minimal but essential study data through a telephone interview when the participant (or informant) wanted to discontinue their full participation. Researchers asked about the course of cognitive symptoms, functional abilities in (I)ADLs (any help or assistance needed in certain activities), and global severity of dementia (CDR). If the participant had received a diagnosis of $\mathrm{MCI}$ or dementia from another physician, the syndrome diagnosis was documented. Despite the participant's refusal to participate in a particular follow-up assessment, some patients agreed to be approached at the next follow up and did return to fully participate in the studies, as shown in Figs. 1 and 2.

\section{Adaptations of study protocol and implementation}

Some changes to the original research protocol were made for better implementation and completion of the studies. Based on the experiences of baseline interview, an evaluation of the reliability of information provided by the participant and the informant was added to the follow up assessments.

As a default, the assessments were carried out in the memory clinics. However, for some participants, it was inconvenient to visit the memory clinic due to immobility or other physical conditions. Where possible, home visits (to the patient's house or nursing home) were implemented in the follow-ups and carried out by a well-trained researcher, to limit study attrition.

\section{Utility and discussion \\ Results}

In the MCI and dementia cohort, 315 and 331 participants were included respectively. Noticeably, more men than women were recruited in the MCI cohort (Table 5), consistently across the three centers, whereas more women were recruited in the Dementia cohort, except in Amsterdam. Participants in the MCI cohort were 5.2 years younger, and had better cognitive performance, functional abilities, physical condition and quality of life, but had higher depression scores on average than those in the Dementia cohort at baseline (Table 6).

Of 315 participants in the 4C-MCI cohort, 90 (29\%) had subjective cognitive decline and $151(48 \%)$ had amnestic MCI. Of 331 participants in the $4 \mathrm{C}$ dementia cohort, 216 (65\%) had probable or possible AD. The majority of the participants experienced a progressive cognitive decline in the phase before the baseline diagnosis, namely $68 \%$ in the MCI cohort, and $89 \%$ in the Dementia cohort, starting at about 3-3.5 years on average before entering in either cohort. Episodic memory was the most severely impaired cognitive domain among MCI patients, whereas among dementia patients, multiple cognitive functions were severely impaired, especially executive functioning, attention and information processing speed. 
Table 5 Baseline demographic characteristics of the participants in the 4C Study

\begin{tabular}{|c|c|c|}
\hline$N(\%)$, unless stated differently & $\begin{array}{l}\text { 4C-MCl cohort } \\
(n=315)\end{array}$ & $\begin{array}{l}\text { 4C-Dementia cohort } \\
(n=331)\end{array}$ \\
\hline $\begin{array}{l}\text { Age at baseline } \\
\text { (years, mean } \pm \text { SD) }\end{array}$ & $69.7 \pm 8.5$ & $74.9 \pm 10.2$ \\
\hline Female sex & $111(35)$ & $182(55)$ \\
\hline Caucasian & $311(99)$ & $326(98)$ \\
\hline \multicolumn{3}{|l|}{ Education } \\
\hline $\begin{array}{l}\text { Low (lower than } \\
\text { middle school) }\end{array}$ & $126(40.0)$ & $142(44.1)$ \\
\hline $\begin{array}{l}\text { Middle (high school/ } \\
\text { vocational education) }\end{array}$ & $78(24.8)$ & $90(28.0)$ \\
\hline High (university) & $111(35.2)$ & $90(28.0)$ \\
\hline \multicolumn{3}{|l|}{ Marital Status } \\
\hline $\begin{array}{l}\text { Married/registered } \\
\text { partnership, cohabiting }\end{array}$ & $244(77.5)$ & $202(61.2)$ \\
\hline Widow/widower & $42(13.3)$ & $93(28.2)$ \\
\hline Single, divorced & $29(9.2)$ & $35(10.6)$ \\
\hline \multicolumn{3}{|l|}{ Living situation } \\
\hline Alone, independently & $59(18.7)$ & $100(30.5)$ \\
\hline With partner and/or children & $242(76.8)$ & $205(62.5)$ \\
\hline Institutionalized living & $9(2.9)$ & $21(6.4)$ \\
\hline Others & $5(1.6)$ & $2(0.6)$ \\
\hline \multicolumn{3}{|c|}{ Informant's relation with the participant } \\
\hline Partner & $224(71.1)$ & $179(54.4)$ \\
\hline Offspring & $60(19.5)$ & $115(35.0)$ \\
\hline Sibling & $7(2.2)$ & $10(3.0)$ \\
\hline Other relative or acquaintance & $23(7.3)$ & $25(7.6)$ \\
\hline
\end{tabular}

By quantitative measures of disease burden (CIRSG), vascular diseases were the most frequent and most severe comorbid category in both cohorts. The total CIRS-G score leaving out the category of psychiatric illness was higher in the dementia than in the MCI cohort. For the AD patients in the dementia cohort, it was found that comorbidities were associated with cognitive performance; frailty was associated with functional abilities at baseline [25]. Comparing older and younger persons with dementia contrasting persons from the $4 \mathrm{c}$ Dementia cohort data with persons from the NeedYD cohort [26], showed that younger persons had less comorbidity and may more often have neurological comorbidities than older persons with dementia [27]. Further studies into the relationship of cognitive decline with comorbidity and frailty are underway. In addition to the objectives described earlier, these will focus on determinants of health-related quality of life and gait speed and grip strength as predictors of cognitive decline in the MCI cohort.
The most prevalent neuropsychiatric symptoms reported by the informants in the MCI cohort were irritability (51\%, average score 5.4 out of 12 in NPI), apathy/indifference $(44 \%, 5.3)$ and depression/dysphoria $(41 \%, 4.7)$. These neuropsychiatric symptoms were also most common in the dementia cohort, with different rankings: apathy/indifference $(51 \%, 6.5)$, depression/ dysphoria $(38 \%, 5.3)$, irritability $(36 \%, 5.3)$. When it occurred, agitation and aggression (mean 3.3; SD 1.13) was most burdening for informants in the MCI cohort. This was also the most burdening symptom in the Dementia cohort $(3.0 \pm 1.3)$.

After 3 follow-ups, 23 subjects $(23 / 90,26 \%)$ classified as SCD at baseline were reclassified as MCI, 23 subjects $(23 / 225,10 \%)$ with MCI reverted to SCD, and 74 subjects (10 subjects with SCD at baseline and 64 subjects with MCI at baseline) progressed to different types of dementia (Table 7). The annual incidence of MCI subjects progressing to dementia was $11 \%(32 / 278)$ in the first 12 months, 7\% (18/260) between 12 and 24 months and $10 \%(24 / 236)$ between 24 and 36 months of follow up. In the dementia cohort, 91 patients (27\%) received at least one different (nosological) diagnosis of dementia during the follow-ups. Of these 91, three participants were rediagnosed as $\mathrm{MCI}$, and one participant went from dementia to $\mathrm{MCI}(12 \mathrm{~m})$ and via again dementia $(24 \mathrm{~m})$ to SCD $(36 \mathrm{~m})$. Thus, in $4(1.2 \%)$ of 331 participants the dementia diagnosis was reconsidered. 16 patients $(5 \%)$ in the MCI cohort and $75(23 \%)$ in the Dementia cohort died during 36 months of follow-up. Studies to develop and validate prognostic rules from these data are underway.

\section{What are the main strengths and weakness?}

One of the main questions for the 4C study was whether the interaction with health status would influence the natural disease course of cognitive disorders, and contribute to the heterogeneity of clinical outcomes. Thus, including participants with comorbidity in the study and getting reliable diagnoses of comorbidities were essential strengths of our studies, leading to more representative patient groups. Prospectively sampling diverse participants with natural disease courses from various routine clinical settings (neurology, geriatrics and old age psychiatry departments) who were representative for the MCI and dementia patients regularly seen in memory clinics was another strength. Finally, cognitive functioning is a central feature of $\mathrm{MCI}$ and dementia. In the $4 \mathrm{C}$ study, in addition to global measures of cognition, a series of standardized and validated neuropsychological tests were available to detail how different cognitive domains changed and to explore the effect of comorbidities on cognitive functioning in different domains over time. While some longitudinal studies 
Table 6 Baseline cognitive, physical and functional characteristics and quality of life of the participants in the $4 C$ Study

\begin{tabular}{|c|c|c|}
\hline Mean $\pm S D$, unless stated differently & $\begin{array}{l}\text { 4C-MCl cohort } \\
(n=315)\end{array}$ & $\begin{array}{l}\text { 4C-Dement } \\
\text { cohort }(n=\end{array}$ \\
\hline \multicolumn{3}{|l|}{ Subclassification cognitive disorder, $N(\%)^{a}$} \\
\hline Subjective cognitive decline & $90(29)$ & n.a. \\
\hline Amnestic $\mathrm{MCl}$ & $151(48)$ & n.a. \\
\hline Non-amnestic $\mathrm{MCl}$ & $71(23)$ & n.a. \\
\hline $\begin{array}{l}\text { Alzheimer's disease } \\
\text { (probable or possible) }\end{array}$ & n.a. & $216(65)$ \\
\hline $\begin{array}{l}\text { Vascular dementia or any dementia } \\
\text { diagnosis with a vascular component }\end{array}$ & n.a. & $71(21)$ \\
\hline $\begin{array}{l}\text { Any other dementia diagnosis } \\
\text { without a vascular component }\end{array}$ & n.a. & $44(13)$ \\
\hline $\begin{array}{l}\text { Self-reported duration of cognitive } \\
\text { problems (years) }\end{array}$ & $3.3 \pm 3.8$ & $3.1 \pm 2.6$ \\
\hline \multicolumn{3}{|c|}{ Self-reported course of cognitive problems, $N(\%)$} \\
\hline Progressive & $213(67.6)$ & $285(89.1)$ \\
\hline Stable & $40(12.7)$ & $14(4.4)$ \\
\hline Fluctuated & $33(10.5)$ & $21(6.6)$ \\
\hline \multicolumn{3}{|l|}{ Cognitive functions $^{b}$} \\
\hline MMSE (range 0-30, lower is worse) & $26.9 \pm 2.6$ & $21.9 \pm 3.7$ \\
\hline $\begin{array}{l}\text { VLT immediate recall (z-score, } \\
\text { lower is worse) }\end{array}$ & $-1.1 \pm 1.2$ & $-2.3 \pm 1.1$ \\
\hline $\begin{array}{l}\text { VLT delayed recall (z-score, lower } \\
\text { is worse) }\end{array}$ & $-1.2 \pm 1.3$ & $-2.4 \pm 0.9$ \\
\hline $\begin{array}{l}60 \text { s animal fluency ( } z \text {-score, lower } \\
\text { is worse) }\end{array}$ & $-0.7 \pm 0.8$ & $-1.7 \pm 0.9$ \\
\hline TMT-A (z-score, lower is worse) & $-0.3 \pm 1.4$ & $-1.7 \pm 1.9$ \\
\hline TMT-B (z-score, lower is worse) & $-0.4 \pm 1.3$ & $-1.8 \pm 1.4$ \\
\hline $\begin{array}{l}\text { SCWT card } 1+2 \text { (z-score, lower } \\
\text { is worse) }\end{array}$ & $-1.2 \pm 1.7$ & $-2.8 \pm 2.5$ \\
\hline $\begin{array}{l}\text { sCWT card } 3 \text { (z-score, lower } \\
\text { is worse) }\end{array}$ & $-1.2 \pm 2.4$ & $-3.5 \pm 3.2$ \\
\hline \multicolumn{3}{|l|}{ Neuropsychiatric symptoms } \\
\hline $\begin{array}{l}\text { GDS-15 (range 0-15, higher } \\
\text { is worse) }\end{array}$ & $3.6 \pm 2.8$ & $3.1 \pm 2.7$ \\
\hline NPI (range $0-144$, higher is worse) & $14.5 \pm 15.0$ & $16.3 \pm 16.3$ \\
\hline $\mathrm{BMI}\left(\mathrm{kg} / \mathrm{m}^{2}\right.$, mean $\left.\pm \mathrm{SD}\right)$ & $26.2 \pm 3.9$ & $25.9 \pm 4.3$ \\
\hline DAD (range $0-100$, lower is worse) & $86.7 \pm 15.7$ & $70.8 \pm 24.1$ \\
\hline \multicolumn{3}{|l|}{ CIRS-G } \\
\hline $\begin{array}{l}\text { Total score (range } 0-52^{c} \text {, higher } \\
\text { is worse) }\end{array}$ & $7.09 \pm 4.87$ & $7.48 \pm 4.94$ \\
\hline $\begin{array}{l}\text { Severity index (total score/number } \\
\text { of categories endorsed, range } 0-4 \text {, } \\
\text { higher is worse) }\end{array}$ & $1.57 \pm 0.51$ & $1.63 \pm 0.55$ \\
\hline $\begin{array}{l}\text { Comorbidity index (number of } \\
\text { categories with score } \geq 2 \text {, range } \\
0-13 \text {, higher is worse) }\end{array}$ & $2.25 \pm 1.93$ & $2.37 \pm 1.90$ \\
\hline \multicolumn{3}{|l|}{$\begin{array}{l}\text { CIRS-G category with score } \geq 2 \text { (at least } \\
\text { moderate disability or morbidity/requires } \\
\text { "first line" therapy), } N(\%)\end{array}$} \\
\hline
\end{tabular}

Table 6 Baseline cognitive, physical and functional characteristics and quality of life of the participants in the $4 \mathrm{C}$ Study (Continued)

\begin{tabular}{|c|c|c|}
\hline Heart & $92(29.2)$ & $90(27.3)$ \\
\hline Vascular & $144(45.7)$ & $170(51.5)$ \\
\hline Hematopoietic & $12(3.8)$ & $25(7.6)$ \\
\hline Respiratory & $74(23.5)$ & $54(16.4)$ \\
\hline Eyes/ears/nose/throat & $54(17.1)$ & $72(21.8)$ \\
\hline Upper gastrointestinal & $48(15.2)$ & $43(13.0)$ \\
\hline Lower gastrointestinal & $28(8.9)$ & $35(10.6)$ \\
\hline Liver & $20(6.3)$ & $21(6.4)$ \\
\hline Renal & $15(4.8)$ & $19(5.8)$ \\
\hline Genitourinary & $57(18.1)$ & $75(22.7)$ \\
\hline Neuromuscular & $40(12.7)$ & $70(21.2)$ \\
\hline Neurological & $75(23.8)$ & $48(14.6)$ \\
\hline Endocrine & 49 (15.6) & $59(17.9)$ \\
\hline \multicolumn{3}{|l|}{ Frailty according Fried Criteria, N (\%) } \\
\hline Not frail ( $\leq 1$ of 5 criteria satisfied), & $219(74.7)$ & $224(68.9)$ \\
\hline Pre-frail (2 of 5 criteria satisfied) & $44(15.0)$ & $55(16.9)$ \\
\hline Frail ( $\geq 3$ of 5 criteria satisfied) & $30(10.2)$ & $46(14.2)$ \\
\hline $\begin{array}{l}\text { EQ-5D (with Dutch weights) (range } \\
0-1 \text {, lower is worse) }\end{array}$ & $0.98 \pm 0.06$ & $0.81 \pm 0.20$ \\
\hline $\begin{array}{l}\text { EQ-5D VAS (range 0-100, lower } \\
\text { is worse) }\end{array}$ & $69.4 \pm 15.6$ & $67.5 \pm 16.9$ \\
\hline \multicolumn{3}{|c|}{ 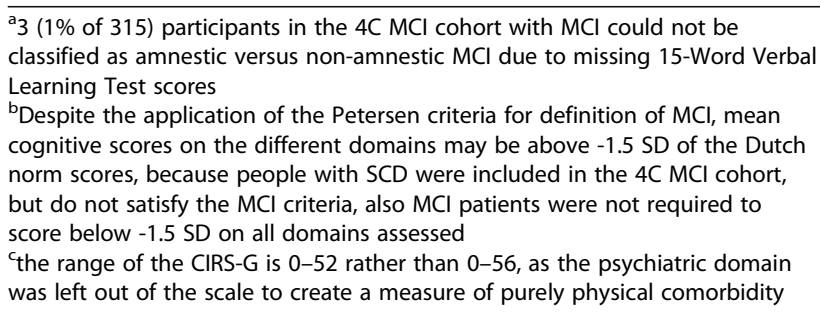 } \\
\hline
\end{tabular}

focusing on risk factor discovery for dementia onset continue to follow persons who develop MCI and/or dementia, dedicated follow up studies are indispensable to understand the more advanced stages of cognitive decline. As such, the $4 \mathrm{C}$ study complements other population-based and clinical MCI and dementia follow up cohorts. In general, population-based (e.g. [28] or [6]) and clinical samples of MCI and dementia (e.g. [29] or [30]) are complementary in that the population-based

Table 7 The incidence of MCl subjects progressing to dementia within the study duration

\begin{tabular}{lllr}
\hline Study time line & \multicolumn{2}{l}{ Number of subjects } & $\%$ \\
\cline { 2 - 3 } & $\mathrm{MCl}$ conversion to dementia & In the cohort & \\
\hline 1 year follow-up & 32 & 278 & 11.5 \\
2 year follow-up & 18 & 260 & 6.9 \\
3 year follow-up & 24 & 236 & 10.1 \\
Total & 74 & 315 & 23.4 \\
\hline
\end{tabular}


studies have the advantage of being systematically sampled from well characterized base populations, whereas the clinical samples are able to add more detail in terms of frequency and type/comprehensiveness of assessment. To maximize the combined value of these data [31], initiatives such as IALSA [32] and COSMIC [33] help to identify datasets as well as provide methodologies in their combined analyses.

Discerning typical disease trajectories based on longterm observation and developing prediction models for disease progression would be beneficial for patient care. However, for frontotemporal dementia, dementia with lewy bodies or other types of dementia, due to limited cases, more effort should be made to include more patients in future studies to increase the power or combining the current samples with other studies.

Attrition was the biggest challenge for the $4 \mathrm{C}$ study, although it is inevitable due to the nature of the disease and the aged population (see Figs. 1 and 2). In the MCI cohort, 225 of 315 (71\%) participants completed all three follow ups $(209 ; 66 \%)$ or completed follow ups until the endpoint of death (16; 5\%). In the Dementia cohort, 207 of $331(63 \%)$ participants completed all three follow ups (142; 43\%) or completed follow ups until the endpoint of death $(65 ; 20 \%)$. Another 10 participants died during the 36 months of follow up, but dropped out of the study for one of the other reasons.

\section{Conclusions}

Sampled in a clinical setting, the $4 \mathrm{C}$ study database complements population-based studies on neurodegenerative disorders in terms of the type of assessment (e.g. comorbidity, frailty, and functional status were repeatedly assessed). The $4 \mathrm{C}$ study complements available databases of clinical cohorts of MCI and dementia patients, because the exclusion criteria were kept to a minimum, to obtain a sample that is representative for the average patient visiting a memory clinic. Cognition, functional abilities, resource use and quality of life were the key outcome domains and their longitudinal changes and dynamic relations will be further explored, also related to endpoints such as death and institutionalization.

\begin{abstract}
Abbreviations
(I)ADLs: (Instrumental) activities of daily living; 4C Study: The Clinical Course of Cognition and Comorbidity in Mild Cognitive Impairment and Dementia Study; AD: Alzheimer's disease; CDR: Clinical Dementia Rating scale; CIRSG: Cumulative Illness Rating Scale for Geriatrics; DAD: Disability Assessment for Dementia; EQ5D: EuroQoL-5D; GDS-15: Geriatric Depression Scale-15; MCI: Mild cognitive impairment; MMSE: MiniMental State Examination; N.A.: Not applicable; NPI: Neuropsychiatric Inventory; SCD: Subjective cognitive decline; SCWT: Stroop Color Word Test (3 subtasks); SD: Standard deviation; TMT: Trail Making Test (part A \& B); VAS: Visual Analogue Scale; VLT: 15-Word Verbal Learning Test
\end{abstract}

\section{Acknowledgements}

The authors would like to thank all the participants and their informants, research assistants and clinical staffs for their continuous contribution for the
4C studies over years. The authors thank Nico Rozendaal for his help with the design of the database and data management of the 4C cohorts. Research of the VUmc Alzheimer center is part of the neurodegeneration research program of the Neuroscience Campus Amsterdam.

\section{Funding}

The 4C studies were supported by Alzheimer Nederland and the VSB foundation. Grant numbers: 20083494 (4C-MCI), 20083495 (4C-Dementia). The funders had no role in study design, data collection and analysis, decision to publish, or preparation of the manuscript. The VUmc Alzheimer Center is supported by Stichting VUmc fonds.

\section{Availability of data and materials}

The $4 \mathrm{C}$ research group actively encourages and welcomes external collaborations. Data are available for researchers with a specific research question. Interested and potential collaborators are invited to contact the study coordinators (Dr. René Melis Rene.Melis@radboudumc.nl or Dr. Inez Ramakers i.ramakers@maastrichtuniversity.nl).

\section{Authors' contributions}

$W L$ and REH contributed equally to the conception of this manuscript and drafted the manuscript and performed the statistical analyses under the direct supervision of IHR and RJM. All other authors participated in the interpretation of the data and revised drafts of the manuscript for important intellectual content. The data collection was performed and coordinated by REH, NS and SMO under the direct supervision of IHR and RJM. PA, RJM, FRV, and MGO conceived the research questions, designed the study and wrote the study proposal. PS and WMF revised the study proposal for important intellectual content. All authors read and approved the final manuscript.

\section{Competing interests}

The authors declare that they have no competing interests.

\section{Consent for publication}

Not applicable.

\section{Ethics approval and consent to participate}

The ethical committees of the institutes Alzheimer Centre Limburg of the Maastricht University Medical Center, and Radboudumc Alzheimer Center, Radboud university medical center participating in this study approved the study. The 4C-MCl cohort was assessed by the METC azM/UM

(NL25214.068.09/MEC 09-3-038) and the 4C-Dementia cohort by the CMO Arnhem-Nijmegen (CMO 0529, registratienummer 2010/046) respectively. The clinician responsible for the care during the memory clinic visit asked whether patients would be willing to consider participation in the $4 \mathrm{C}$ study. If so, they were provided with written study information and a visit was scheduled with a research assistant to obtain written informed consent from the participant and an informant and to complete the baseline assessments.

\section{Author details}

${ }^{1}$ Radboud Institute of Health Sciences, Department of Geriatric Medicine \& Radboudumc Alzheimer Centre, Radboud University Medical Center, PO Box 9109(House post 925), 6500 HB Nijmegen, The Netherlands. ${ }^{2}$ Alzheimer Centre Limburg, School for Mental Health \& Neuroscience, Maastricht University Medical Centre, Maastricht, The Netherlands. ${ }^{3}$ Donders Institute for Brain, Cognition and Behaviour, Department of Geriatric Medicine \& Radboudumc Alzheimer Centre, Radboud University Medical Center, Nijmegen, The Netherlands. ${ }^{4}$ Alzheimer Center \& Department of Neurology, VU University Medical Center, Neuroscience Campus, Amsterdam, The Netherlands. ${ }^{5}$ Alzheimer Center \& Department of Neurology, Department of Epidemiology and Biostatistics, VU University Medical Center, Amsterdam, The Netherlands.

Received: 8 April 2016 Accepted: 10 November 2016 Published online: 25 November 2016

\section{References}

1. Prince M, Wimo A, Guerchet M, Ali GC, Wu YT, Prina M. World Alzheimer report 2015: the global impact of dementia - an analysis of prevalence, incidence, cost and trends. London: Alzheimer's Disease International; 2015. 
2. Visser PJ, Kester A, Jolles J, Verhey F. Ten-year risk of dementia in subjects with mild cognitive impairment. Neurology. 2006;67(7):1201-7.

3. Leoutsakos JM, Forrester SN, Corcoran CD, et al. Latent classes of course in Alzheimer's disease and predictors: the Cache County Dementia Progression Study. Int J Geriatr Psychiatry. 2015;30(8):824-32.

4. Fotuhi M, Hachinski V, Whitehouse PJ. Changing perspectives regarding late-life dementia. Nat Rev Neurol. 2009;5(12):649-58.

5. Marengoni A, Rizzuto D, Wang HX, Winblad B, Fratiglioni L. Patterns of chronic multimorbidity in the elderly population. J Am Geriatr Soc. 2009;57(2):225-30.

6. Melis RJ, Marengoni A, Rizzuto D, et al. The influence of multimorbidity on clinical progression of dementia in a population-based cohort. PLoS One. 2013;8(12):e84014.

7. Leoutsakos JM, Han D, Mielke MM, et al. Effects of general medical health on Alzheimer's progression: the Cache County Dementia Progression Study. Int Psychogeriatr. 2012;24(10):1561-70.

8. Boyle PA, Buchman AS, Wilson RS, Leurgans SE, Bennett DA. Association of muscle strength with the risk of Alzheimer disease and the rate of cognitive decline in community-dwelling older persons. Arch Neurol. 2009;66(11):1339-44.

9. Buchman AS, Schneider JA, Leurgans S, Bennett DA. Physical frailty in older persons is associated with Alzheimer disease pathology. Neurology. 2008; 71(7):499-504.

10. Petersen RC, Smith GE, Waring SC, Ivnik RJ, Tangalos EG, Kokmen E. Mild cognitive impairment: clinical characterization and outcome. Arch Neurol. 1999;56(3):303-8.

11. Jessen F, Amariglio RE, van Boxtel M, et al. A conceptual framework for research on subjective cognitive decline in preclinical Alzheimer's disease. Alzheimers Dement. 2014;10(6):844-52.

12. Diagnostic and statistical manual of mental disorders : DSM-IV. 4th ed. Washington, DC: American Psychiatric Association; 1994

13. McKhann G, Drachman D, Folstein M, Katzman R, Price D, Stadlan EM. Clinical diagnosis of Alzheimer's disease: report of the NINCDS-ADRDA Work Group under the auspices of Department of Health and Human Services Task Force on Alzheimer's Disease. Neurology. 1984;34(7):939-44.

14. Roman GC, Tatemichi TK, Erkinjuntti T, et al. Vascular dementia: diagnostic criteria for research studies. Report of the NINDS-AIREN International Workshop. Neurology. 1993;43(2):250-60.

15. Neary D, Snowden JS, Gustafson L, et al. Frontotemporal lobar degeneration: a consensus on clinical diagnostic criteria. Neurology. 1998; 51(6):1546-54.

16. McKeith IG, Galasko D, Kosaka K, et al. Consensus guidelines for the clinical and pathologic diagnosis of dementia with Lewy bodies (DLB): report of the consortium on DLB international workshop. Neurology. 1996;47(5):1113-24.

17. Aalten P, Ramakers I, Biessels G, et al. The Dutch Parelsnoer Institute neurodegenerative diseases; methods, design and baseline results. BMC Neurol. 2014;14(1):1060.

18. Miller MD, Paradis CF, Houck PR, et al. Rating chronic medical illness burden in geropsychiatric practice and research: application of the Cumulative IIIness Rating Scale. Psychiatry Res. 1992;41(3):237-48.

19. Fried LP, Tangen CM, Walston J, et al. Frailty in older adults: evidence for a phenotype. J Gerontol A Biol Sci Med Sci. 2001;56(3):M146-56.

20. Searle SD, Mitnitski A, Gahbauer EA, Gill TM, Rockwood K. A standard procedure for creating a frailty index. BMC Geriatr. 2008;8:24.

21. Gelinas I, Gauthier L, McIntyre M, Gauthier S. Development of a functional measure for persons with Alzheimer's disease: the disability assessment for dementia. Am J Occup Ther. 1999;53(5):471-81.

22. Yesavage J, Sheikh J. Geriatric Depression Scale (GDS): recent evidence and development of a shorter version. Clin Gerontol. 1986;5(1-2):165-73.

23. Cummings JL. The Neuropsychiatric Inventory: assessing psychopathology in dementia patients. Neurology. 1997;48(5 Suppl 6):S10-6.

24. EuroQol G. EuroQol-a new facility for the measurement of health-related quality of life. Health Policy. 1990;16(3):199-208.

25. Oosterveld SM, Kessels RP, Hamel R, et al. The influence of co-morbidity and frailty on the clinical manifestation of patients with Alzheimer's disease. J Alzheimers Dis. 2014;42(2):501-9.

26. van Vliet D, Bakker C, Koopmans RT, Vernooij-Dassen MJ, Verhey FR, de Vugt ME. Research protocol of the NeedYD-study (Needs in Young onset Dementia): a prospective cohort study on the needs and course of early onset dementia. BMC Geriatr. 2010;10:13.

27. Gerritsen AA, Bakker C, Verhey FR, de Vugt ME, Melis RJ, Koopmans RT. Prevalence of comorbidity in patients with young-onset Alzheimer disease compared with late-onset: a comparative cohort study. J Am Med Dir Assoc. 2016;17(4):318-23.

28. Tschanz JT, Corcoran CD, Schwartz S, et al. Progression of cognitive, functional, and neuropsychiatric symptom domains in a population cohort with Alzheimer dementia: the Cache County Dementia Progression study. Am J Geriatr Psychiatry. 2011;19(6):532-42.

29. Beekly DL, Ramos EM, Lee WW, et al. The National Alzheimer's Coordinating Center (NACC) database: the Uniform Data Set. Alzheimer Dis Assoc Disord. 2007;21(3):249-58.

30. Mueller SG, Weiner MW, Thal $L$, et al. Ways toward an early diagnosis in Alzheimer's disease: the Alzheimer's Disease Neuroimaging Initiative (ADNI). Alzheimers Dement. 2005;1(1):55-66.

31. Erten-Lyons D, Sherbakov LO, Piccinin AM, et al. Review of selected databases of longitudinal aging studies. Alzheimers Dement. 2012;8(6):584-9.

32. Hofer SM, Piccinin AM. Integrative data analysis through coordination of measurement and analysis protocol across independent longitudinal studies. Psychol Methods. 2009;14(2):150-64.

33. Sachdev PS, Lipnicki DM, Kochan NA, et al. COSMIC (Cohort Studies of Memory in an International Consortium): an international consortium to identify risk and protective factors and biomarkers of cognitive ageing and dementia in diverse ethnic and sociocultural groups. BMC Neurol. 2013;13:165.

34. Morris JC. The Clinical Dementia Rating (CDR): current version and scoring rules. Neurology. 1993;43(11):2412-4.

35. Folstein MF, Folstein SE, McHugh PR. "Mini-mental state". A practical method for grading the cognitive state of patients for the clinician. J Psychiatr Res. 1975;12(3):189-98.

36. Van der Elst W, van Boxtel MP, van Breukelen GJ, Jolles J. Rey's verbal learning test: normative data for 1855 healthy participants aged 24-81 years and the influence of age, sex, education, and mode of presentation. J Int Neuropsychol Soc. 2005;11(3):290-302.

37. Lindeboom J, Schmand B, Tulner L, Walstra G, Jonker C. Visual association test to detect early dementia of the Alzheimer type. J Neurol Neurosurg Psychiatry. 2002;73(2):126-33.

38. Wechsler D. Wechsler Memory Scale: administration and scoring manual. 3rd ed. San Antonio: The Psychological Corporation; 1997.

39. Lezak MD. Neuropsychological assessment. 3rd ed. New York; Oxford: Oxford University Press; 1995

40. van der Elst W, van Boxtel MP, van Breukelen GJ, Jolles J. The Letter Digit Substitution Test: normative data for 1,858 healthy participants aged 24-81 from the Maastricht Aging Study (MAAS): influence of age, education, and sex. J Clin Exp Neuropsychol. 2006;28(6):998-1009.

41. Van der Elst W, Van Boxtel MP, Van Breukelen GJ, Jolles J. The Stroop colorword test: influence of age, sex, and education; and normative data for a large sample across the adult age range. Assessment. 2006;13(1):62-79.

42. Reitan RM. Validity of the Trail Making Test as an indicator of organic brain damage. Percept Mot Skills. 1958:8:271-6.

43. Warrington EK, James M. The visual object and space perception battery. Bury St. Edmunds: Thames Valley Test Company; 1991.

\section{Submit your next manuscript to BioMed Central and we will help you at every step:}

- We accept pre-submission inquiries

- Our selector tool helps you to find the most relevant journal

- We provide round the clock customer support

- Convenient online submission

- Thorough peer review

- Inclusion in PubMed and all major indexing services

- Maximum visibility for your research

Submit your manuscript at www.biomedcentral.com/submit
) Biomed Central 